\title{
THE SHARPENING OF SOME INEQUALITIES VIA ABSTRACT CONVEXITY
}

\author{
GABIL AdILOV AND GÜLTEKIN TINAZTEPE
}

Abstract. One of the application areas of abstract convexity is inequality theory. In this work, the authors seek to derive new inequalities by sharpening well-known inequalities by the use of abstract convexity. Cauchy-Schwarz inequality, Minkowski inequality and well-known mean inequalities are studied in this sense, concrete results are obtained for some of them.

Mathematics subject classification (2000): 26D07.

Keywords and phrases: Abstract convexity, functional inequalities, harmonic-geometric-arithmetic mean inequalities, global optimization.

\section{REFERENCES}

[1] G. R. Adilov And G. Tinaztepe, On the Asymptotic Aggregation Problem of High Dimensional Systems, System and Control Letters, Vol. 55 (5), p. 414-417, 2006.

[2] E. BeCKeNBACH AND R. Bellman, Inequalities, Springer-Verlag, 1961.

[3] S. S. DRAGOMIR, J. DutTA, AND A. M. Rubinov, Hermite-Hadamard Type Inequalities for Increasing Convex Along Rays Functions, Analysis (Munich) 24, no. 2, 171-181.

[4] S. S. DRAGOMIR AND C. E. M. PEARCE, Quasi-convex Functions and Hadamard's Inequality, Bulletin of Australian Mathematical Society, 57(1998), 377-385.

[5] C. E. M. PeArCe AND A. M. Rubinov, P-functions, Quasiconvex Functions and Hadamard-type Inequalities, Journal of Mathematical Analysis and Applications, 240 (1999), 92-104.

[6] A. M. Rubinov, Abstract Convexity: Example and Applications, Optimization, 47, 1-33, 2000.

[7] A. M. RuBINov, Abstract convexity and global optimization, Kluwer Academic Publishers, 2000.

[8] A. M. RuBINOv AND Z. Y. Wu, Optimality Conditions in Global Optimization and Their applications, Mathematical Programming (Series B), accepted.

[9] E. V. SHARIKOV, Hermite-Hadamard Type Inequalities for Increasing Radiant Functions, Journal of Inequalities in Pure and Applied Mathematics, Volume 4, Issue 2, Article 47, 2003.

[10] I. SINGER, Abstract Convex Analysis, John Wiley and Sons Inc. New York, 1997. 